\title{
Nuit et jour de la poésie de bouche à oreille
}

\section{Ivan (Ivy) Bielinsky}

\section{(2) OpenEdition}

\section{Journals}

\section{Édition électronique}

URL : http://journals.openedition.org/edl/1167

DOI : $10.4000 /$ edl. 1167

ISSN : 2296-5084

\section{Éditeur}

Université de Lausanne

\section{Édition imprimée}

Date de publication : 15 septembre 2016

Pagination : 7-12

ISBN : 978-2-940331-49-9

ISSN : 0014-2026

\section{Référence électronique}

Ivan (Ivy) Bielinsky, « Nuit et jour de la poésie de bouche à oreille », Études de lettres [En ligne], 3 | 2016, mis en ligne le 15 septembre 2019, consulté le 19 décembre 2020. URL : http://

journals.openedition.org/edl/1167; DOI : https://doi.org/10.4000/edl.1167 
NUIT ET JOUR DE LA POÉSIE DE BOUCHE À OREILLE

\author{
Dire directement sans salmigon... DIRE \\ Avant que la mort vienne nous rai... DIRE \\ Ce que la vie aura voulu nous DIRE \\ Du tout au tout sans jamais défaillir (...) \\ La fin du MOI \\ Et le début de NOUS-rire ${ }^{1}$.
}

Depuis longtemps, le spectacle attire la foule. Autrefois cantonné à des lieux de représentations spécifiques, il déborde aujourd'hui jusqu'à envahir l'espace intime de la maison - radio, internet, télévision. Néanmoins, le spectacle en salle ou à l'extérieur mobilise encore la foule. On comprend que les poètes, sans doute lassés des coteries et des réunions mondaines, aient tenus à monter sur scène pour partager le poème au-delà du seul lectorat. De toute façon, voilà bien longtemps que les amateurs du genre invitent des poètes dans une pléthore d'évènements littéraires - rencontres, discussions, récitals. Il va de soi qu'à un moment donné, les poètes eux-mêmes aient voulu présenter des spectacles de poésie - entendez par là, des récitals de poèmes plus ou moins mis en scène.

Au Québec, jamais rien n’a atteint en succès la mythique Nuit de la poésie. Présentant la crème des poètes contemporains et réservant une place de choix à la relève, cet évènement historique mis en images par Jean-Claude Labrecque a fait date. Le poème et les gens, pour une fois, étaient au même endroit. Une grâce qui n'arrive que trop rarement. Depuis, de nombreux excellents recueils ont paru, des maisons d'édition ont vu le jour et des dizaines d'évènements à teneur poétique

I. Ivy, Slamérica (ensemble multi-supports), Montréal, Le lézard amoureux, 2008, p. 13. 
sont nés sans pour autant «augmenter» de façon significative le degré de poétisation de la société. Faut-il en conclure que la société se montre réfractaire à la poésie? Non, à condition d'éviter l'amalgame poème et poésie. Et s'il apparaît que les gens se montrent peu intéressés par la production littéraire poétique contemporaine, il en va autrement de la poésie elle-même, comme en témoigne le succès du slam.

Le slam de poésie (traduction libre de poetry slam), par son impertinence - il précipite ni plus ni moins les poètes dans l'agora (d'aucuns diront «l'arène») - contraint l'albatros claudiquant à se tenir debout. Sans gêne ni manière, il se prête avec complaisance au jeu du spectacle, transformant le poète de l'ombre en tribun éclairé. Qui plus est, il n'orchestre aucune sélection chez les participants, pas plus que dans le public. Candidement, le slam dit: «Vous avez écrit des poèmes? Très bien, venez les dire... et le public décidera ». Leurre? Absolument. Mais au passage, pendant le processus, des gens qui n'auraient jamais mis les pieds dans un récital de poèmes se font injecter de la poésie (une énergie, une atmosphère, un regard, une fièvre) à leur insu. Et en redemandent. En vingt-cinq ans, le slam a fait bien plus pour la poétisation du monde qu'un siècle de poésie littéraire. Non par la richesse de ses trouvailles langagières, mais par son désir de communiquer, de partager. Avec lui, la poésie s'affranchit du livre et revient à la vie.

L'oralité constitue l'enjeu du slam. Le poème, le slameur et l'auditoire s'y rapportent. Hors de cette modalité, pas de slam possible. Ancré dans la réalité, au présent de ce qui est, le slameur parle et les vibrations de sa parole pénètrent en même temps des dizaines de cortex cérébraux. Les gens ne font pas qu'écouter: ils respirent et réagissent. Ils s'érigent en faux contre le caractère définitif de l'œuvre. Le livre, le Mp3 ou le clip vidéo n'offre pas de telles ouvertures. Toutes sortes d'événements se produisent dans la réalité: quelqu'un tousse, une porte claque, un téléphone sonne. Déclamer sur scène, conduire une automobile, faire l'amour exigent la même disponibilité, le même degré de concentration et de souci de l'autre. Le poème joue sur le fil de l'attention. Triompher dans ce contexte tient de l'exploit.

Le slameur comme le public ne dispose pas du poème à sa guise. Un vers dit, un vers disparu. Le train du présent ne s'arrête jamais. Alors le poème revient sur ses dires, ressasse des formules pour mieux se faire comprendre. Les rimes, les vers métriques, les jeux de sonorités, autant d'appuis pour escalader le poème en marche. Un moment de flottement 
et le public bascule! Le poème bien en sécurité dans la chaleur des pages n'endure jamais pareille pression. Si quelque chose dérange le lecteur, il y reviendra plus tard; si un passage lui échappe, il peut à loisir le relire. Les poètes qui critiquent l'apparente facilité des poèmes oraux devraient s'estimer heureux: aucun slameur ne peut sans risque se réfugier derrière l'incommunicabilité du poème.

En revanche, la déclamation a ses avantages: la griserie créatrice se partage, les fruits sont palpables - et goûteux. On parle à des gens et les gens répondent. Ainsi va la communication. Déclamer, certes; parler directement aux hommes et aux femmes de son époque, encore mieux. Voir une métaphore éclater au visage d'un auditoire n'a pas son pareil. Je deviens une sorte de magicien, de créateur en cours (comme on dit téléchargement en cours)... Je constate de visu les effets de mon travail. Et cela m'inspire pour la suite.

Chaque performance remodèle le poème: les salles et les auditoires varient, les sentiments que je souhaite évoquer aussi. Sans cesse remis sur le feu, le poème se transforme: des vers disparaissent, des formules s'imposent. L'oralité se soucie moins de l'objet que de l'effet. Le poème doit s'adapter. L'écrit devient vassal de la parole. La vie l'emporte sur la mort.

C'est de prime abord ce qui m'a frappé dans le slam: l'effet du poème oral sur une foule hétéroclite. Cela m’a profondément marqué. J’ai senti à ce moment-là que la poésie avait techniquement trouvé le moyen de se révéler au monde. Si la Nuit de la poésie a su démontrer la coïncidence extraordinaire des poèmes et d'une certaine frange de la population à une époque donnée, le slam de poésie, lui, renouvelle à chaque fois le miracle de la poésie partagée par tous.

En créant la première scène de slam francophone à Montréal en octobre 2006, mon intention avouée était de donner une corde de plus à l'arc des poètes. L'idée d'ouvrir la scène à n'importe qui n'avait pas fait son chemin de la France jusqu'ici, en Amérique, où la scène ouverte, couramment appelée «micro ouvert» (traduction littérale de Open Mic), prospérait depuis des décennies. Fidèle au poetry slam nord-américain comme je le suis toujours -, j'avais l'ambition de canaliser notre génie poétique dans une entreprise d'évangélisation de masse. Par le recours à la mécanique du slam (autrement dit: les règles), je voyais les poètes renouer avec leurs fonctions ancestrales en communiquant leurs visions, leurs prophéties, leurs sortilèges à une foule envoûtée. La réalité, on s'en doute, fut quelque peu différente. 
D'une part, l'engouement des poètes fut de courte durée. En moins de deux ans, la plupart de ceux qui avaient manifesté de l'intérêt non seulement ne fréquentaient plus la scène de slam, mais passaient le plus clair de leur temps à la dénigrer. D’autre part, le succès de Grand Corps Malade aidant, beaucoup de gens en vinrent à penser que le slam était une nouvelle forme de poésie de style urbain, hip-hop, le condamnant à un effet de mode. Les définitions que donnent du slam les dictionnaires Larousse et Robert vont encore en ce sens.

Dans ce contexte, la popularité de notre Grand slam québécois ne cesse de m'étonner. Près de 400 personnes s'y déplacent à chaque année pour venir entendre les slameurs des quatre coins de la province. L'atmosphère unique, la ferveur et la réponse enthousiaste du public a même fait dire à Marc Smith (fondateur du slam) qu'il retrouvait chez nous la passion des Allemands - qui vouent au slam un véritable culte. A plus petite échelle, c'est ce que je vis à chaque mois sur ma bonne vieille scène à Montréal. J'entends des novices et des plus expérimentés rivaliser d'adresse pour séduire un public chaque fois différent. Je les accompagne depuis le début, je les vois se remémorer inlassablement leurs poèmes avant que le spectacle ne commence. Nous manifestons le même respect envers ceux qui sont venus nous écouter. Nous sommes à leur service. Le slam est un événement collectif où l'on soumet toutes les formes de poésie à l'approbation de la foule. C'est un pari risqué. Mais nous sommes les missionnaires de la poésie. Ni les prêtres (entre convertis), ni les théologiens. Simplement des slameurs: porteurs de parole. Créatures du spectacle, éphémères et si humaines. Nous quittons les palais, les temples, les bibliothèques pour marcher parmi nos semblables, les païens. Et nous les convertissons.

Une nuit de la poésie dure ce qu'elle dure. Les écrits s'envolent au lever du jour. Etrangement ensuite s'élèvent des murmures, puis des voix qu'on ne soupçonnait pas. C'est un garagiste, un comptable, un serveur, un médecin, un chômeur. C'est un enfant qui s'exclame, un amoureux qui s'emporte. Une fois le livre écrit et refermé, le vaste univers nous fait signe. L'émotion affleure les lèvres, une image en jaillit. Tout se ramasse soudainement en quelques portions du langage et se transmet.

S'intéresser au slam au-delà des effets de mode, des slogans et des mésinterprétations, c'est faire face à l'enjeu même de notre époque: la parole, la communication. Certes, la poésie n'arrêtera pas la fonte des glaciers. Pourtant, elle seule saura nous donner l'heure juste au moment 
des choix à faire. Un homme, c'est un corps, un esprit, mais aussi et surtout une sensibilité - un cœur, dirait-on métaphoriquement. Je travaille pour que cette sensibilité prenne la place qui lui revient dans toutes nos activités: qu'elle participe au débat public, qu'elle s'assoie même à la table des décideurs. Le but du slam est que la flamme de la poésie se propage, qu'importe le porteur ou la porteuse: car, à chaque fois qu'on la passe, elle renaît.

Ivan Bielinsky (Ivy)

Montréal, 15 août 2015 
